\section{Do lower IQ children attain concepts more slowly than children of higher IQ?}

ELI SALTZ and HELEN HAMILTON, Center for the Study of Cognitive Processes, Wayne State University, Detroit, Mich. 48202

The suggestion is made that previous findings which report a higher error score on concept-learning tasks for low-IQ than for high-IQ children may be confounded by certain statistical artifacts related to the mixed criterion generally used, e.g., 10 successive correct or a maximum of 96 trials. One hundred third-grade children were presented a concept-learning task. Data from all $S s$ were consistent with previous findings. However, when $S$ s were separated into solvers and nonsolvers, data for solvers only showed no difference in mean errors as a result of $I Q$ level. The critical factor which has been overlooked in previous studies is the difference in frequency of solvers at each IQlevel.

A number of studies have found that, under some conditions at least, the mean number of errors to criterion in concept attainment is greater for lower-IQ children than for children of higher IQ (e.g., Osler \& Fivel, 1961; Oslet \& Trautman, 1961; Wolff, 1967). These results have typically been interpreted as indicating that lower-IQ children take longer to solve the concepts.

This type of interpretation appears to stem from implicit assumptions about the concept-attainment process. From the incremental S-R position, for example, it would seem reasonable that lower-IQ Ss would require more trials to develop a given level of habit strength compared to the number of trials required by higher-IQ Ss.

The present paper suggests that previous data on this topic are confounded by certain statistical artifacts. Typically, a mixed criterion has been used in analyzing the data, e.g., 10 consecutive correct trials or 150 trials, whichever occurs first. This type of mixed criterion presents a serious difficulty; it is well known that Ss who solve concept tasks do so rather quickly, while the remaining $S s$ appear unable to solve in a reasonable number of trials. It appears that if the correct hypotheses concerning solution are reasonably high in the S's hierarchy of hypotheses, solution will occur; otherwise solution is unlikely. On this basis, it is reasonable to conceptualize two classes of Ss, solvers and nonsolvers.

The present paper will examine the position that high- and low-IQ children who solve do not differ in speed of concept solution; the greater mean errors to solution for lower-IQ Ss found in previous studies is due to the smaller number of solvers among lower-IQ Ss.

Two concept tasks were investigated. One is the same as a task used by Osler \& Trautman (1961), in which mean errors were found to be greater for lower-IQ than for higher-IQ children, using the mixed criterion of solution described above. The other task is a variation of the first task.

$$
\text { METHOD }
$$

The Ss were 100 third-grade children, randomly assigned, 50 each, to two task conditions, $\mathbf{A}$ and $\mathbf{B}$. The median IQ for all Ss was 102.5 (for Task A Ss, 101.5; for general ability (Science Research Associates) administered by the school approximately 6 months prior to the study.

Stimulus materials were random patterns of $1,2,3,4$, or 5 black dots on white cards. Pairs of patterns were presented simultaneously, one pattern of each pair being formed of two dots

The concept to be learned in Task A was, simply, "twoness," e.g., S pointed to the number of each pair formed of the two-dot pattern.

In Task B, the concept was also "twoness," but with the restriction that only two-dot patterns having a particular arrangement were correct. In the latter task, therefore, a correct response was either pointing to the "correct" two-dot patterns, or stating that neither of the patterns of the pair was correct. "Correct" two-dot patterns were presented on $50 \%$ of the trials in Task B. (These tasks have been described in detail in Saltz \& Hamilton, in press.)

Criterion performance on either task was 10 correct responses or a maximum of 96 trials.

\section{RESULTS}

Table 1 presents the mean number of Task B Ss, 103.0). IQs were based on tests of errors made by Ss in both task groups. It is readily apparent that below-average Ss made a greater number of errors on both types of task (column headed "All Ss"). In this respect, the data agree with the results presented in Osler \& Trautman (1961) and Osler \& Fivel (1961). An unweighted means analysis (Task by IQ Level) yields $F(1,96)=6.81, p<.05$ for IQ, and $F(1,96)=36.86, p<.001$ for Task; the interaction was not significant.

The proportion of Ss who solved the concept in each task group was greater at the higher IQ levels. Seventy-five per cent of the above-average Ss solved the concept of Task A (18 of 24), while only $62 \%$ of the below-average Ss solved (16 of 26). The concept of Task B was solved by $42 \%$ of the above-average-IQ Ss (11 of 26 ), and by $17 \%$ of the below-average Ss (4 of 24). Although a chi-square analysis showed no significant difference in the frequency of solvers and nonsolvers at the two IQ levels, the fact that there were a greater number of nonsolvers (Ss requiring the maximum 96 trials) at the lower IQ levels necessarily inflates the mean error score for the low-IQ groups. Significant differences in mean errors by high- and low-IQ Ss, which previously have been reported, become ambiguous, since the high error score by low-IQ Ss may be attributable to frequency of nonsolvers at this IQ level rather than to the quality of their performance.

To examine the above issue in greater detail, Ss were divided into solvers and nonsolvers at each IQ level. Reference to Table I shows that IQ level had little effect on mean errors of Ss who solved. Mean errors were 8.3 for above-average solvers and 9.4 for below-average solvers on Task $A$, and 13.7 for above-average solvers and 14.8 for below-average solvers on Task B.) Unweighted means analysis of variance showed no significant difference in errors for solvers at the two IQ levels on either task.

The suggestion might be made that Ss in the below-average groups who are higher in IQ would be more apt to solve. The breakdown of IQ of solvers and nonsolvers in Table 2 indicates that this is not the case.

Table 1

Mean Numbers of Errors Made by All Ss Combined and by Solvers and Nonsolvers Separately for Tasks $A$ and $B$

\begin{tabular}{|c|c|c|c|c|c|c|}
\hline \multirow[b]{2}{*}{ I.Q. Group } & \multicolumn{2}{|c|}{ All Ss } & \multicolumn{2}{|c|}{ Solvers } & \multicolumn{2}{|c|}{ Nonsolvers } \\
\hline & Mean & $\mathbf{N}$ & Mean & $\mathbf{N}$ & Mean & $\mathbf{N}$ \\
\hline \multicolumn{7}{|l|}{ Task A } \\
\hline $\begin{array}{l}\text { Above average } \\
\text { Below average }\end{array}$ & $\begin{array}{l}18.4 \\
25.5\end{array}$ & $\begin{array}{l}24 \\
26\end{array}$ & $\begin{array}{l}8.3 \\
9.4\end{array}$ & $\begin{array}{l}18 \\
16\end{array}$ & $\begin{array}{l}48.7 \\
51.3\end{array}$ & $\begin{array}{r}6 \\
10\end{array}$ \\
\hline Difference & 7.1 & & 1.1 & & 2.6 & \\
\hline \multicolumn{7}{|l|}{ Task B } \\
\hline $\begin{array}{l}\text { Above average } \\
\text { Below average }\end{array}$ & $\begin{array}{l}41.7 \\
57.7\end{array}$ & $\begin{array}{l}26 \\
24\end{array}$ & $\begin{array}{l}13.7 \\
14.8\end{array}$ & $\begin{array}{r}11 \\
4\end{array}$ & $\begin{array}{l}61.3 \\
66.3\end{array}$ & $\begin{array}{l}15 \\
20\end{array}$ \\
\hline Difference & 16.5 & & 1.1 & & 5.0 & \\
\hline
\end{tabular}


Table 2

1.Q. of Solvers and Nonsolvers at Each Intelligence Level

\begin{tabular}{lccccc}
\hline & \multicolumn{3}{c}{ Task A } & & \multicolumn{2}{c}{ Task B } \\
\cline { 2 - 3 } \cline { 5 - 6 } $\begin{array}{l}\text { I.Q. } \\
\text { Group }\end{array}$ & Solvers & $\begin{array}{c}\text { Non- } \\
\text { solvers }\end{array}$ & & Solvers & $\begin{array}{c}\text { Non- } \\
\text { solvers }\end{array}$ \\
\hline Above & 114.5 & 115.0 & 109.0 & 109.0 \\
Average & 11.5 & 6 & & 11 & 15 \\
N & 18 & 6 & & & \\
Below & 90.0 & 93.5 & & 95.5 & 93.5 \\
Average & 90.0 & 10 & & 4 & 20 \\
N & 16 & 10 & & &
\end{tabular}

IQ of solvers and nonsolvers is virtually identical at both IQ levels. In addition, Ss who solved, whether above or below average in $\mathrm{IQ}$, required approximately the same number of trials to do so. The median number of trials required was 12.5 and 11.5 , respectively, for above- and below-average Ss on Task A, and 16 and 19, respectively, on Task B. It does not appear that "given enough trials the low IQ child will gradually come to solve the concept."

\section{DISCUSSION}

The present data strongly suggest that, within the normal range (IQ 75.150), IQ is unrelated to speed of solution for children who solve. Intelligence appears to be more strongly related to likelihood of solution than to rate of solution. Perhaps solvers and nonsolvers among the lower-IQ children differ in some fundamental abilities. The work of Whitman (1966) on cognitive styles in concept attainment suggests this as a possibility. Whitman reports that compatibility between cognitive style and task are more critical than IQ in determining concept performance. On the other hand, the difference between solvers and nonsolvers may lie along dimensions which permit remedial training. For example, some work suggests that lower-IQ children may be less likely to engage in hypothesis-testing behavior unless trained to do so (e.g., Osler \& Weiss, 1962). Possibly, relevant hypotheses are less likely to be high in the hierarchy of lower-IQ children.

The present findings appear potentially important in suggesting that previous notions concerning the relationship between IQ and concept attainment may have been seriously in error.

\section{REFERENCES}

OSLER, S., \& FIVEL, M. Concept attainment: I. The role of age and intelligence in concept attainment by induction. Joumal of Experimental Psychology, 1961, 62, 1-8.

OSLER, S., \& TRAUTMAN, G. Concept attainment: II. Effect of stimulus complexity upon concept attainment at two levels of intelligence. Journal of Experimental Psychology, 1961, 62, 9-13.

OSLER, S., \& WEISS, S. Studies in concep attainment: III. Effects of instructions at two levels of intelligence. Journal of Experimental Psychology, 1962, 63, 538-533.

SALTZ, E., \& HAMILTON, $H$. The role of intelligence in precriterion concept attainmen by children. Journal of Experimental Psycho logy, 1969, 81, 191-192.

WHIIMAN, $R$. N. Concept attainment as a function of intelligence. Dissertation Abstracts, 1966

WOLFF, J. L. Concept attainment, intelligence and stimulus complexity: An attempt to replicate Osler and Trautman (1961). Joumal of Experimental Psychology, 1967, 73, 488-490. NOTE

1. The present study was supported by National Science Foundation Grant GB 6583. The writers wish to express their gratitude to Mrs. Carol Born Principal of Elmira School, St. Clair Shores Michigan, for her cooperation in making Ss available for this study. transfer when using a generalization measure in the transfer stage of an $A B, A^{\prime} B$ paradigm, where $A$ and $A^{\prime}$ were associated words, and $B$ was a nonsense syllable. Palermo \& Jenkins (1964) (using an AB, AC, AX paradigm, where $A B$ words were either lowly or highly associated, AC words were not associated directly but only through mediated associations of either high or low strength, and $\mathrm{AX}$ words were not associated), with children as $\mathrm{Ss}$, demonstrated that their association norms would predict not only the learning of pairs directly associated (AB), but also the learning of pairs which were associated indirectly via a mediated response (AC). Further, in an experiment by McGehee \& Schultz (1961), conducted to determine how language habits inferred from free-association norms might mediate the learning of verbal paired associates, it was concluded that free-association norms were "critical" in defining associative chains.

The above studies have related the association value of pairs to mediation in varying manners. However, the present study attacked the problem by using a somewhat different procedure than had been attempted thus far. The purpose of this study was to more completely define the effect of association value of word pairs in the standard $\mathrm{AB}, \mathrm{BC}, \mathrm{AC}$ mediation paradigm by manipulating between-stage association value. The expectation was that manipulation of the associative strength of word pairs in different stages of the paradigm, while at the same time holding the association values of the word pairs in other stages constant, would modify the transfer and mediation which occurred in the paradigm. There was no test for mediation per se in the present study. By now, the mediation phenomenon in the $\mathrm{AB}, \mathrm{BC}, \mathrm{AC}$ paradigm is so well accepted by Es in the field that it seemed more efficacious for the purposes of the present study to accept as a basic premise that mediation would occur, and to direct the experimental procedure toward manipulating that mediation.

\section{SUBJECTS}

The 64 Ss ( 32 males, 32 females; median $C A=19)$ were undergraduates at the University of South Florida. Thirty-seven were enrolled in an introductory psychology course and received extra credit for their participation. Since not all Ss had participated in similar experiments, $S$ assignment, while random, was done so that the Ss known to be naive were equally distributed across all conditions.

\section{PROCEDURE}

Subjects were run individually using the $A B, B C, A C$ paradigm under standard paired-associate anticipation procedure.

Four lists of eight word-pairs each were constructed from Palermo \& Jenkins's 